\title{
Teaching EFL in the Local Culture: Tunisian Students of English as a Case Study
}

\section{Yosra Sellami-Sellami}

Ph.D. student, Faculty of Letters and Humanities of Sfax, University of Sfax, Tunisia, yosra.sellami28@gmail.com

\begin{abstract}
This research explored the attitudes and motivations of first-year students of English enrolled at the Faculty of Letters and Humanities of Sfax, Tunisia, during the academic year 2018-2019 towards learning English as a foreign language. Attitudes and motivations were investigated according to three variables: culture shock, interest in the English language, and ethnocentrism. Analysis of the relationship between language and culture paved the way for examining students' reactions towards learning English as a foreign language. Students feel very differently about English as a way of knowing the world, networking, and living a full life of a global citizen. Attitudes range from discomfort, anxiety, and confusion. A questionnaire was used to collect data about students' attitudes and motivational orientations towards learning English as a Foreign Language. The study indicated that most students do not like English-speaking people and reject some of their cultural values. It also showed that these students choose to learn English primarily for instrumental reasons. This paper concludes with solutions aiming to reduce the difficulties teachers of English as a Foreign Language encounter in the local Tunisian cultural context.
\end{abstract}

Keywords: attitudes and motivations towards EFL, instrumental motivation, integrative motivation, ethnocentrism, the Five Cs

\section{INTRODUCTION}

The starting point for this article is teaching the English language goes hand in hand with teaching Anglo-American culture. The corollary is that language learning cannot occur in a cultural vacuum and in isolation from the cultural norms in which the language originates. This assumption undergirds the Official Tunisian Program of Teaching English to Basic Education Levels, which states the following objectives: "As a means of communication, English will foster learner self-expression as well as appropriate interaction with peers and other interlocutors, which, in turn, will ensure access to universal culture through Anglophone contexts" (as cited in Hermessi, 2017, p. 211). Learning is referred to as "a relatively permanent change in behaviour or potential behaviour as a result of strengthened experience or training" (Hediansah \& Surjono 2019, p. 2). Henceforth, teaching English to Tunisian students as part of their educational program implies teaching language in different linguistic and cultural environments.

The present study aims to discuss the psychological effects and changes that might be expected and consider how these changes affect teaching English in a Tunisian context.

\section{Statement of the problem}

Learners who enter a language classroom do not carry cultural baggage that they can put aside and leave outside the door. Instead, they are an embodiment of the culture which they share with others. In this respect, it is worth mentioning Kohlberg (1958) whose theory presupposes that learning and learners' moral development are interrelated (Musa \& Martha, 2020, p. 2). A Tunisian student who enters class to learn English belongs to and is, in part, shaped by a national culture, which naturally

Citation: Sellami-Sellami, Y. (2021). Teaching EFL in the local culture: Tunisian students of English as a case study. Anatolian Journal of Education, 6(2), 125-134. https://doi.org/10.29333/aje.2021.6210a 
has some overlaps with the cultures of other international societies. This study investigates the attitudes of first-year students of English towards learning English as a foreign language by looking into three significant variables: culture shock, ethnocentrism, and interest in the English language. The latter is related to two types of motivation, instrumental and integrative.

\section{Research questions}

1. Do Tunisian students of English have negative attitudes towards foreign languages?

2. How do Tunisian students of English look upon English-Speaking communities in the world and their culture?

3. Are Tunisian students of English instrumentally or integratively motivated to learn English?

\section{Definition of concepts}

1. Rabe (2009) defines culture as being definitely "learned and inherited" and as passing from one generation to the next. "It is one of the controlling influences in the way we live, think, speak and behave" (p. 12). Consequently, when experiencing an "unpleasant feeling causing persons to reevaluate both the new host and their own home culture", culture shock occurs (Pedersen, 1995, p. 1).

2. Ethnocentrism is the assumption that one's own culture is superior to any other culture. According to Bennett, being an ethnocentric person "means that you make life choices and act based on the assumption that your world view is superior". Ethnocentrism is the tendency to look at other cultures through the eyes of one's own culture. It also implies negatively valuing the culture of others as inferior and, thus, prevents students of a foreign language from learning it effectively (as cited in Marginson \& Sawir, 2011, p. 57).

3. Instrumental orientation reflects the practical value and advantages of learning a new language. For Gardner $(1985,2001)$, it is the desire to achieve proficiency in a new language for practical reasons. Such reasons include "getting a better job or requiring a higher pay, reading technical materials, passing required exams, meeting the requirements for school or university graduation or translation work" (as cited in Lu \& Li, 2008, p. 91).

4. Integrative orientation refers to the desire to achieve proficiency in a new language to participate in the life of the community that speaks the target language (Gardner, 2001, as cited in $\mathrm{Lu} \mathrm{\&} \mathrm{Li}, 2008$, p. 91). In such a way, learners feel that learning English will help them understand English people and the English way of life, make good friends, think, and behave as English people do. Gardner (2001) claims that the desire to integrate the target language community reflects a personal interest towards the other people and the culture they represent. Thus, "openness" to the foreign culture, which refers to "an absence of ethnocentrism", is achieved (ibid).

\section{METHOD}

\section{Participants}

This study's population consists of first-year students of English enrolled at the Faculty of Letters and Humanities of Sfax during the academic year 2018-2019. Eighty-two students answered the questionnaire, based on convenience sampling, as described in the following section.

\section{Description of the questionnaire and its sub-parts}

The choice of the questionnaire as the main data collection instrument in this study is based on the ability of this instrument to reach a large number of students in dispersed classes and to collect data relatively quickly considering the time constraints.

The questionnaire contains three sections designed to answer the research questions. Each section covers one of the three variables addressed in this article. The first section deals with the variable of culture shock, which comes in two parts. The first seeks to answer whether Tunisian students like 
English-speaking communities. The second one aims to determine if Tunisian students consider all that is different from their own culture strange and unacceptable.

The second section of the questionnaire tackles ethnocentrism, and it also comes in two parts. First, students are asked to state if they think their ethnic group has superiority over others. Then, they are prompted to state if they think that learning English affects their own cultural identities. The purpose of this question is to find out how they view their own culture.

The third section of the questionnaire deals with the variable of interest in learning the English language to a high level. Here, students are instructed to explain their motivation to learn English. The answer to this question will shed light on the causes that stimulate their interest in mastering English. In other words, the goal is to determine if they are instrumentally or integratively motivated. Students are asked to choose if they prefer to read an English book, newspaper, or magazine to know what constitutes an urgent need for them. Finally, students are requested to rate their proficiency levels and their previous experience with English. Analysis and interpretation of students' responses is the object of the following section.

\section{FINDINGS AND DISCUSSION}

This section is concerned with describing first-year students' attitudes towards English as a foreign language by investigating three variables: culture shock, ethnocentrism, and interest in the English language. Each variable will be dealt with in two steps: first, the results will be described, then discussed.

\section{Culture shock variable}

The first part of the questionnaire requests students to state their feelings towards English-speaking people in general. $52 \%$ answered that they do not like them, while $22 \%$ said they like them. The remaining $26 \%$ stated they were indifferent.

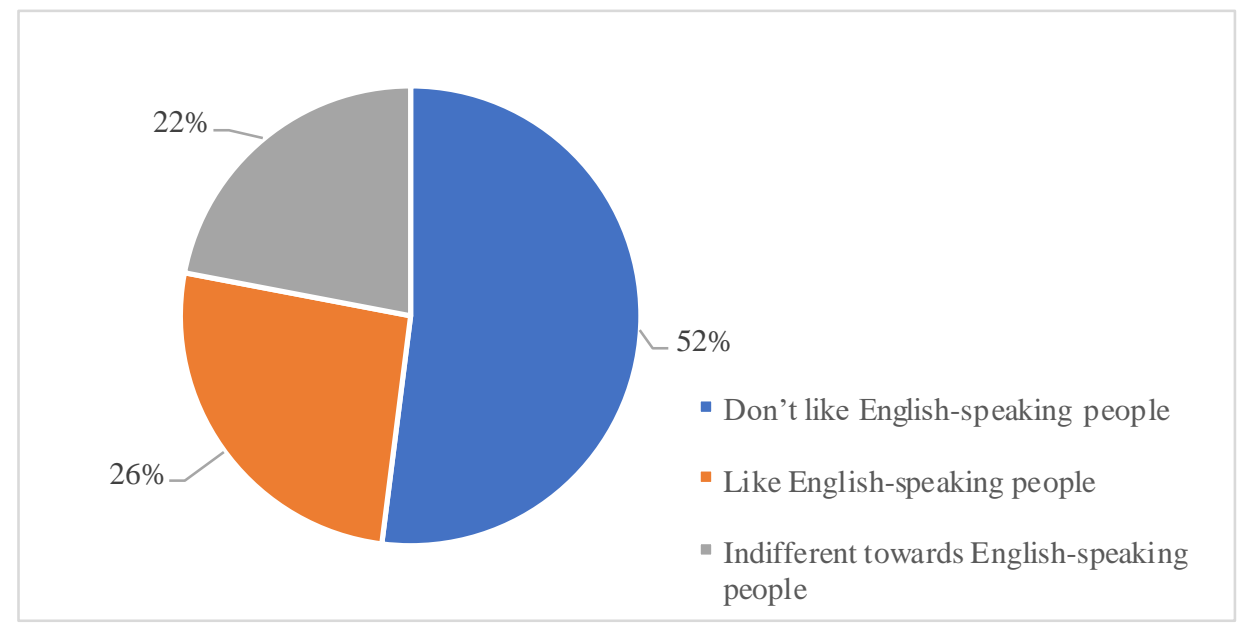

Figure 1

Students' feelings towards English-speaking people

When asked to state their reactions to four aspects of English culture, students seemed to appreciate how the English spend their free time, and 64\% showed that they were keenly interested. However, only $36 \%$ gave favorable opinions concerning weddings, family life, and cinema. 


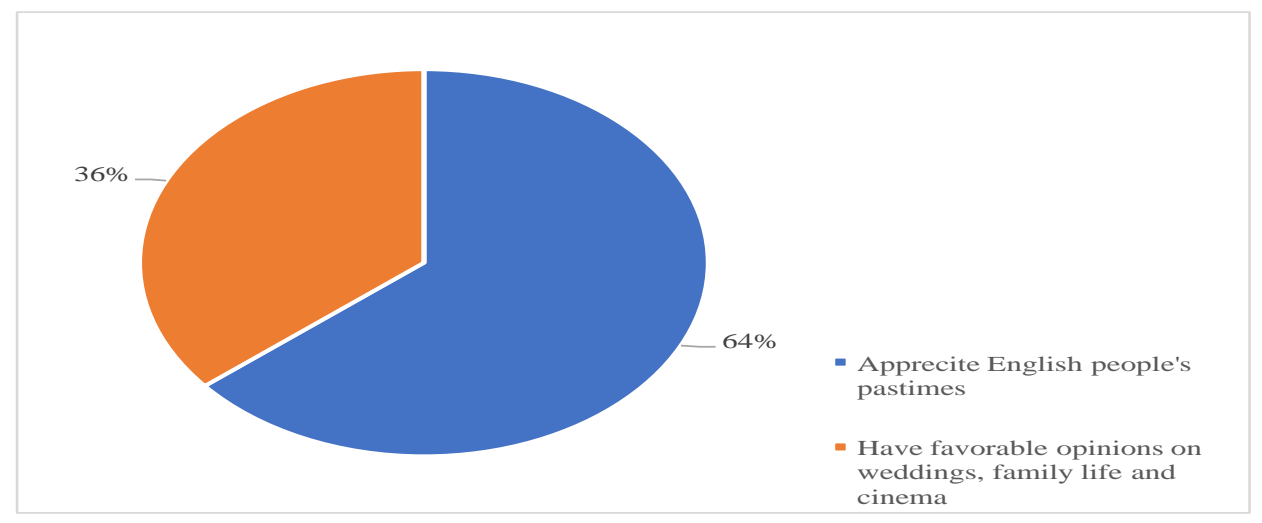

Figure 2

Students' levels of interest in some aspects of English culture

A possible interpretation of the percentages in Figures 1 and 2 is that students who enrol in an English course carry in their mind's ambivalent ideas about the English language. These ideas are a mixture of curiosity and discomfort. During their exposure to the new language, students discover aspects of the culture that are different from their own culture.

It seems that these students view English as both rich and beautiful, but they do not consider English as a carrier of a cultural component of interest to them (Karahan, 2007). This feeling may be because students have a strong desire to learn the language but not the culture. One possible reaction may be to reject all that is different from their own culture. These students may consider that all that is different from their own culture strange and, possibly, unacceptable. According to Brown (1994), culture shock is a state which ranges from "mild irritability to deep psychological panic and crisis" (p. 170). However, this should not be exaggerated. Culture shock, though it reflects manifestations of a crisis, can also be viewed as an experience that leads to a higher degree of self-awareness and personal growth (ibid, p. 171).

\section{The ethnocentrism variable}

The second questionnaire invites students to think about whether their ethnic group is superior to others. $57 \%$ answered positively, while $43 \%$ disagreed with this statement.

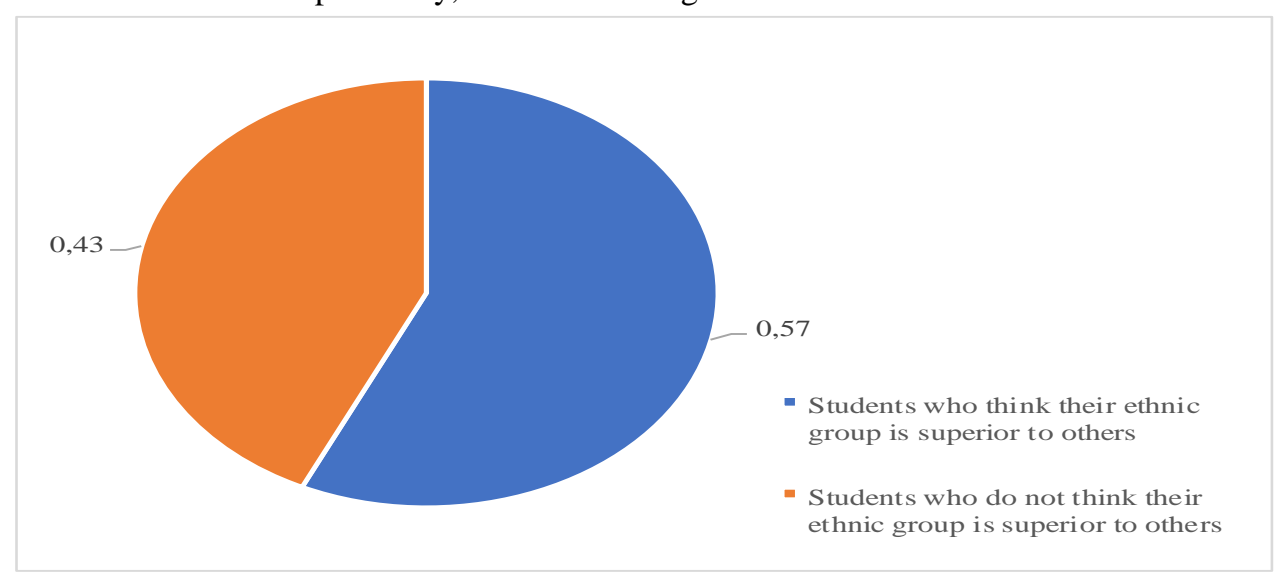

Figure 3

Students' ethnic group is or is not superior to others 
Students were asked if learning English negatively impacts their cultural identities. 82\% of students disagreed with this statement, while the remaining 18\% answered that learning English does affect their cultural identities.

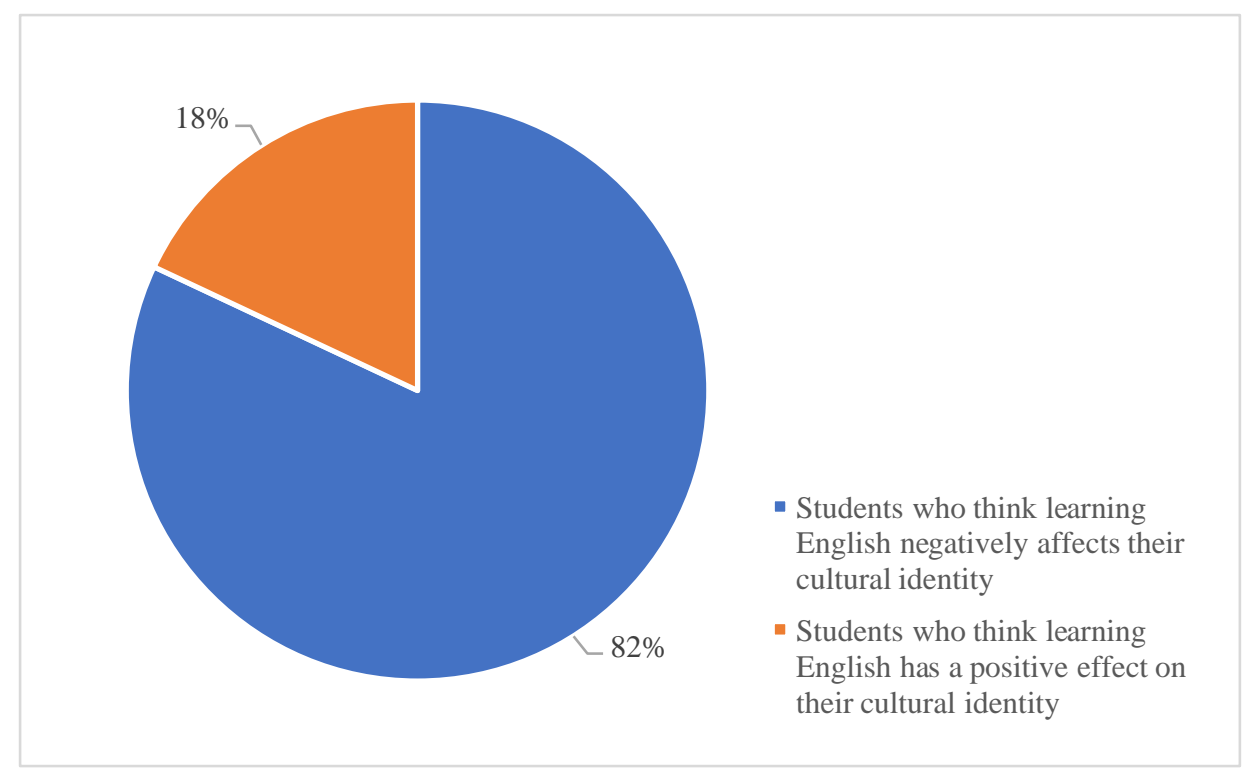

Figure 4

Percentage of students who agreed that learning English negatively or positively affects their cultural identity

The answers to these questions reveal that students tend to believe that every person thinks that their family or country is better than any other and that the problems they had gone through result from foreign ideas. Besides, they think that the culture they were born into and the experiences they have gone through are the standards against which all other cultures should are to be measured.

It transpires from Figure 3 and Figure 4 that it is difficult for many students to familiarize themselves with aspects of a different culture, especially if they lack exposure to foreign cultures. The meanings of a particular language link back to the culture of the speakers of that language. Therefore, understanding those meanings requires understanding that culture.

Most students seem to resist being influenced by foreign customs as if they were trying to protect their identities from being tainted by alien beliefs and thoughts.

\section{Interest in the English language}

In the section on interest in English, students are asked to state their reasons for learning English to a high level. The results showed that $42 \%$ opined that learning English offers opportunities to travel overseas for tourism, satisfies their curiosity about members of the English-speaking world, and speaks like native speakers. 52\% declared they choose to study English because the job market requires superior English proficiency. English also has the merit of making overseas travel for the job easier. Finally, English permitted them to move up the social ladder. However, only $6 \%$ stated their motivation to learn English to a superior level was instrumental and integrative at once. 


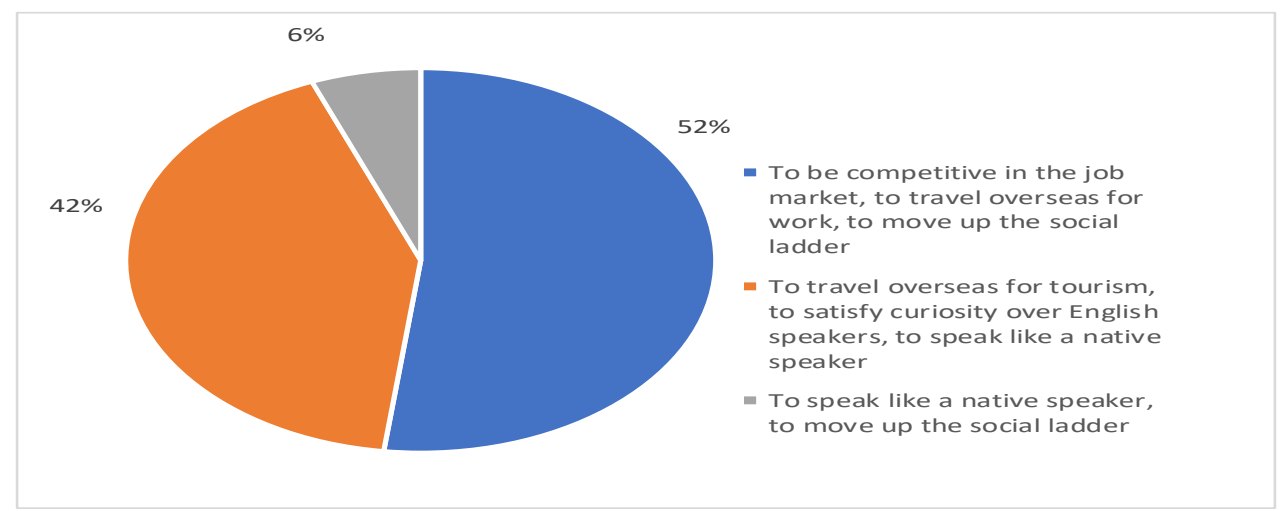

Figure 5

Students' motivations for learning English

Regarding students' motivations to learn English, 46\% expressed their desire to read books in English. $33 \%$ stated they were interested in reading English newspapers, and only $21 \%$ said they wanted to master English to read English magazines.

The factors affecting language learning explain students' diverse needs and goals for learning English; it has been found that students generally give instrumental reasons more frequently than integrative reasons for studying the English language. $52 \%$ of the students stated that they were interested in learning English only as a means to an end, such as getting a good job or gaining some social or economic reward. These utilitarian/practical purposes may stem from the fact that English is an international language. Thus, first-year students may feel the need to learn English for professional purposes.

$42 \%$ of these students are integratively motivated, i.e., they wish to integrate themselves into the target language community and become a part of that community. Falk (1978) thinks such students seem to "like the people that speak the language, admire the culture and have a desire to become familiar with or even integrate into the society in which the language is used" (as cited in Oroujlou \& Vahedi, 2011, p. 996).

Only 6\% of students had 'mixed' motivation to study English. These students appeared to be generally enthusiastic about learning English and, at the same time, take advantage of this level of enthusiasm to move to a higher social class.

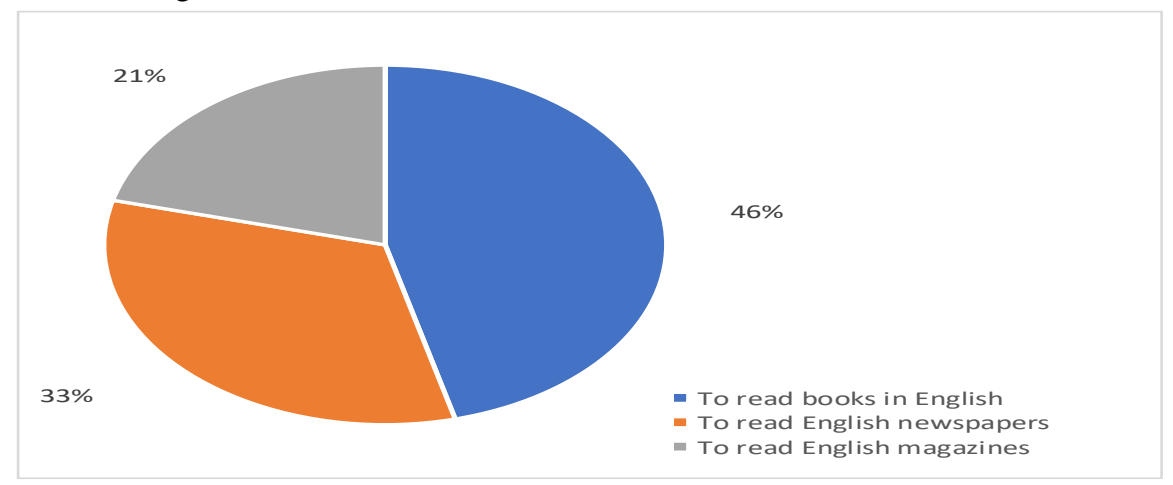

Figure 6

Students' favourite readings in English 
In the last of the questionnaire, students evaluated their proficiency levels and previous experience with learning English. $26 \%$ described it as low, $44 \%$ described it as average, and $21 \%$ described it as good. The remaining $9 \%$ claim it is excellent.

It transpires from these percentages that most students are interested in reading English books rather than newspapers or magazines. They may understand books to mean only textbooks assigned in the curriculum; they may feel a more urgent need to read books originally written in English. Another reason could be the lack of local newspapers and magazines written in English; students may not be equally interested in reading about issues that do not directly concern them in newspapers and magazines.
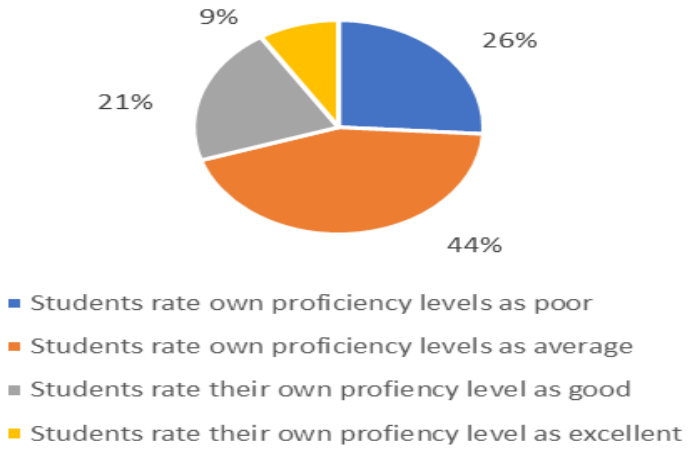

Figure 7

Students' self-rating of their English proficiency levels

The combined percentage of 'average, good, and excellent proficiency' levels equals $74 \%$. This is the total percentage of students who report that they have attained the desired proficiency level either in comprehension, production, or both. This self-report means these students think they can manage the course requirements. The remaining $26 \%$ evaluated their proficiency levels as poor. They may have negative attitudes leading to "decreased motivation" and "unsuccessful attainment of proficiency" (Brown, 2000, p. 181); these students report that they cannot go beyond the basics and are unable to catch up with their courses. Thus, they are likely to encounter difficulties developing their proficiency levels, which leads them to be individually unmotivated to learn the target language.

The questionnaire results suggest that students have different attitudes toward the English culture. Teachers need to deal with these differences through, for example, the use of the Five C's as explained in the following section.

\section{Suggestions to overcome difficulties}

Two solutions are advanced to overcome the difficulties encountered by local teachers teaching English in the local Tunisian culture. The first has to do with the Five C's which, "represent a holistic, communicative approach to language learning" (Schwartz, 2002, p. 115). The Second highlights the teacher's role in integrating the Five $\mathrm{Cs}$ in their academic activities and tasks.

The Five Cs

In 1995, The American Council on the Teaching of Foreign Languages established eleven National Standards for Foreign Language Learning and organized them into five goal areas, known as the Five Cs, namely communication, cultures, connections, comparisons, and communities (Schwartz, 2002).

The communication goal area 
The primary purpose of learning any foreign language is to be able to communicate. Knowledge of English is valued if used to communicate with its native speakers and other English users worldwide. Most communication is oral/aural, which is where the emphasis should be laid (Schwartz, 2002). Students need stimulation to use English in the classroom, to respond in English, and use it in speech; a significant hurdle facing teachers of the English language is the need to persuade their students to speak English to each other during the English class. Simply put, teachers need to persuade their students that English serves their communicative needs in the English class.

The cultures goal area

Teaching a foreign language cannot occur in isolation from the culture in which the language is used. As Schwartz (2002) states, teaching a foreign language outside the cultural context in which it is spoken has no meaning. Students need to know the words necessary to engage in interaction with native speakers and the customs and manners that govern social interactions in the foreign culture. Tunisian students should avoid equating being human with being Tunisian and viewing everything from a Tunisian vantage point. In such a way, they will realize that other cultures are valid forms of human expression and experience; being exposed to different cultures works against narrowmindedness and paves the way for greater tolerance.

The connections goal area

The connection goal focuses on the importance of using the foreign language "as a tool to access and process information in a diversity of contexts" (Schwartz, 2002, p. 114). The teacher introduces the linguistic and cultural English context. Students understand the general meaning of what is taught and respond to it appropriately through the context. It is the teacher's responsibility to encourage students to practice the language in different contexts.

The comparisons goal area

When students compare their local language and culture with English language and culture, their awareness of syntax, morphology, and phonology increases (Schwartz, 2002). Moreover, their understanding of culture and the factors that constitute it is enhanced (Schwartz, 2002).

The communities goal area

This fifth goal area emphasizes using the target language in communities and contexts both inside and outside the academic environment (Schwartz, 2002).

The role of the teacher

Local Teachers teaching English as a foreign language to Tunisian students need to develop methods and techniques of presenting aspects of English culture and should not confine themselves to teaching what is in the textbook. Most important of all is how teachers create connections between language and culture that are interesting and non-judgmental. It is essential to embed culture in the teaching of a language, and it is equally essential to avoid chauvinism in teaching it. As Bochner (1982) points out, local learners' attitudes towards the English culture need to be changed by a re-ordering of their cognitive structures, which helps them be "different persons" (as cited in Byram, 1989, p. 103). In other words, students' acceptance of the English culture helps them learn to be more tolerant and accept differences.

Just as conversation learning requires accurate pronunciation, and just as correct grammar requires practice, knowledge of culture comes as a natural consequence of the language learning process. It is a fact that the Communicative Language Teaching (CLT) Approach focuses on language and culture. In this respect, it is worth mentioning the eight CLT principles summarized by Berns (1990, as cited in Savignon, 2002, p. 6). 
1. Language teaching is based on a view of language as communication. A language is a social tool that speakers use to make meaning; speakers communicate about something to someone for some purpose, either orally or in writing.

2. Diversity is recognized and accepted as part of language development and use in second language learners and users, as it is with first language users.

3. A learner's competence is considered in relative, not absolute, terms.

4. More than one variety of a language is accepted as a viable learning and teaching model.

5. Culture is instrumental in shaping speakers' communicative competence in their first language and in other languages they may learn.

6. No single methodology or fixed set of techniques is prescribed.

7. Language use serves the ideational, interpersonal, and textual functions, and it is related to developing learners' competence in these functions.

8. Learners must be engaged in doing things with language - that is, that they use language for various purposes in all phases of learning.

Based on the above principles, CLT has switched emphasis to the active use of language as a learning technique. It stresses using authentic language as the material from which learners learn. Besides acquiring linguistic competence, learners need to acquire aspects of the target language culture and move from monocultural to intercultural competence. Linguistic competence refers to mastering the grammar of the language as a "system of rules" (Chomsky, 2015, p. 14). This system encapsulates syntactic, phonological, and semantic components (ibid).

\section{CONCLUSION}

Culture is a unifying factor upon which group identity rests. It involves communication and interaction between the group members, who consequently gain awareness of their identity. The group starts to perceive their cultural environment through the filters of their worldview and then acts upon that perception, however biased it may be. When learners are exposed to another culture, their reactions may be anger, shock, frustration, repulsion, or even confusion.

Some mottoes like "language and culture are inseparable", "Language and culture are intimately linked," and "language is culture and culture is language" prove the inseparability of language and culture at a global level (Risager, 2006, p. 1). Therefore, the fundamental aspects of people's culture influence the way they use language. Students' reactions to English as a foreign language are expected since they 'see themselves and their compatriots not as a culture but as 'standard,' or 'right,' and the rest of the world as made up of cultures, which are conglomerates of strange behavior" (Valdes, 1986, p. vii). Once they relinquish these notions and recognize that there is such a thing as cultural relativism and cultural universality, students will start to look at other languages non-judgmentally (ibid). In this way, they accept the plurality of thought and culture.

\section{REFERENCES}

Brown, H. D. (1994). Principles of language learning and teaching ( $3^{\text {rd }}$ ed). Englewood Cliffs, NJ: Prentice-Hall Regents.

Brown, H. D. (2000). Principles of language learning and teaching (4 ${ }^{\text {th }}$ ed). White Plains, NY: Longman. 
Byram, M. (1989). Cultural studies in foreign language education. Clevedon, Philadelphia: Multilingual Matters.

Chomsky, N. (2015). Aspects of the theory of syntax (50th-anniversary ed). Cambridge, Massachusetts: The MIT Press.

Hediansah, D., \& Surjono, H. D. (2019). Building motivation and improving learning outcomes with Android-based physics books: Education 4.0. Anatolian Journal of Education, 4(2), 1-10.

Hermessi, T. (2017). An Evaluation of the place of culture in English education in Tunisia. In S. Hidri., and C. Coombe (Eds.), Evaluation in foreign language education in the Middle East and North Africa (pp. 203-220). Switzerland: Springer.

Karahan, F. (2007). Language attitudes of Turkish students towards the English language and its use in Turkish context. Journal of Arts and Sciences, 7, pp. 73-87.

Lu, X., and Li, G. (2008). Motivation and achievement in Chinese language learning: A comparative analysis. In A. W. He and Y. Xiao (Eds.), Chinese as a Heritage Language: Fostering Rooted World Citizenry (pp. 89-109). Mānoa: National Foreign Language Resource Center.

Marginson, S., and Sawir, E. (2011). Ideas for intercultural education. New York, NY: Palgrave Macmillan.

Musa, M., \& Martha, A. A. (2020). School management mechanisms and control of discipline among pupils in primary schools: An analysis of discipline in upper primary level. Anatolian Journal of Education, 5(1), 1- 16.

Oroujlou, N., and Vahedi, M. (2011). Motivation, attitude, and language learning. Procedia- Social and Behavioral Sciences, 29, pp. 994-1000.

Pedersen, P. (1995). The five stages of culture shock: Critical incidents around the world. Westport, Conn.: Greenwood Press.

Rabe, M. (2009). Culture shock! Living and working abroad. Eugene, Or.: Resource Publications.

Risager, K. (2006). Language and culture: Global flows and local complexity. Clevedon: Multilingual Matters Ltd.

Savignon, S. J. (2002). Communicative language teaching: Linguistic theory and classroom practice. In S. J. Savignon (Ed.), Interpreting communicative language teaching: Contexts and concerns in teacher education (pp. 1-27). New Haven: Yale University Press.

Schwartz, A. (2002). National Standards and the diffusion of innovation: Language teaching in the United States. In S. J. Savignon (Ed.), Interpreting Communicative Language Teaching: Contexts and Concerns in Teacher Education (pp. 112-130). New Haven: Yale University Press.

Valdes, J. M. (1986). Culture bound: Bridging the cultural gap in language teaching. Cambridge: Cambridge University Press. 